\begin{tabular}{|c|c|}
\hline Title & $\begin{array}{l}\text { Use of orbitrap-MSMS and QSAR analyses to estimate mutagenic transformation products of iopamidol generated } \\
\text { during ozonation and chlorination }\end{array}$ \\
\hline Author(s) & Matsushita, Taku; Hashizuka, Masahiro; Kuriyama, Taisuke; Matsui, Y oshihiko; Shirasaki, Nobutaka \\
\hline Citation & $\begin{array}{l}\text { Chemosphere, 148, 233-240 } \\
\text { https:/doi.org/10.1016/.chemosphere.2016.01.037 }\end{array}$ \\
\hline Issue Date & 2016-04 \\
\hline Doc URL & http:/hdl.handle.net/2115/68645 \\
\hline Rights & $\begin{array}{l}\text { (9 2016. This manuscript version is made available under the CC-BY-NC-ND } 4.0 \text { license } \\
\text { http://creativecommons.org/icenses/by-nc-nd/4.0/ }\end{array}$ \\
\hline Rights(URL) & http://creativecommons.org/icenses/oy-nc-nd/4.0/ \\
\hline Type & article (author version) \\
\hline Additional Information & There are other files related to this item in HUSCAP. Check the above URL. \\
\hline File Information & final-manuscript.pdf \\
\hline
\end{tabular}

Instructions for use 


\title{
Use of orbitrap-MS/MS and QSAR analyses to estimate mutagenic transformation products of iopamidol generated during ozonation and chlorination
}

\author{
Taku Matsushita ${ }^{1 *}$, Masahiro Hashizuka ${ }^{2}$, Taisuke Kuriyama ${ }^{2}$, Yoshihiko Matsui ${ }^{1}$ and Nobutaka Shirasaki ${ }^{1}$ \\ ${ }^{1}$ Faculty of Engineering, Hokkaido University, N13W8, Sapporo 060-8628, Japan \\ ${ }^{2}$ Graduate School of Engineering, Hokkaido University, N13W8, Sapporo 060-8628, Japan \\ *Corresponding author: taku-m@eng.hokudai.ac.jp; +81-11-706-7279.
}

Graphic abstract:<smiles>CC(O)C(=O)Nc1c(I)c(C(=O)NC(CO)CO)c(I)c(C(=O)NC(CO)CO)c1I</smiles>

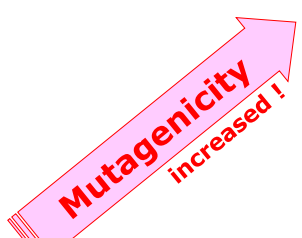

$\underline{\text { I opamidol }}$

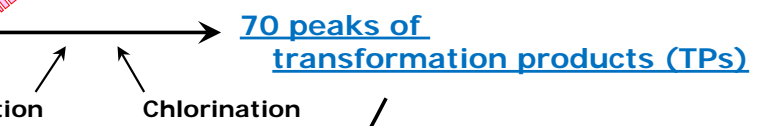

Ozonation Chlorination

Quantitative structure-activity relationship (QSAR) analysis

\section{2 candidate TPs \\ suspected to contribute to mutagenicity}<smiles>CC(=O)NC(=O)c1c(Cl)c(N)cc(C(N)=O)c1I</smiles><smiles>O=C(N[C@@H](CO)C(=O)O)c1c(I)c(I)c([N+](=O)[O-])c(I)c1C(=O)OCCO</smiles>

Abstract: The effects of two water purification processes (ozonation, and chlorination after ozonation) on the mutagenicity of a solution containing iopamidol (X-ray contrast medium) were investigated by using the Ames assay. No mutagenicity was observed during ozonation. In contrast, mutagenicity was induced by the ozone-treated iopamidol-containing solution after subsequent chlorination, indicating that mutagenic transformation-products (TPs) were generated. Ten of 70 peaks detected on the LC/MS total ion chromatogram (TIC) of the ozone-treated iopamidol-containing solution after chlorination had a positive correlation $\left(r^{2}>0.6\right)$ between their peak areas and the observed mutagenicity, suggesting that TPs detected as these peaks may induce mutagenicity. To narrow down the possible contributors to the observed mutagenicity, we compared the areas of the peaks on the TIC-charts with and without chlorination. Of the ten peaks, six were also detected in the ozone-treated iopamidol-containing solution without chlorination, which did not induce mutagenicity, indicating that these peaks were not related to the observed mutagenicity. Accurate $m / z$ values and MS/MS analysis with an orbitrap MS of the remaining four peaks revealed that two of them represented the same TP in the negative and positive ion modes. The three remaining TPs were assessed in four quantitative structure-activity relationship models for predicting Ames mutagenicity. At least one model predicted that two of the three TPs were mutagenic, whereas none of the models predicted that the other TP was a mutagen, suggesting that the former TPs, estimated 
3-hydroxy-2-\{3-[(2-hydroxyethoxy)carbonyl]-2,4,6-triiodo-5-nitrobenzoyl $\}$ amino)propanoic acid, could be the candidate compounds that contributed to the observed mutagenicity.

Keywords: Ames assay; disinfection by-product; drinking-water treatment; mutagenicity; X-ray contrast medium.

\section{Introduction}

X-ray contrast media, used in medical diagnostics for imaging internal body structures such as soft tissues, internal organs, and blood vessels, are most often based on the triiodobenzene molecule into which some side chain groups are incorporated to enhance water solubility and lower toxicity (Christiansen, 2005; Hainfeld et al., 2006). Iodinated X-ray contrast media (ICM) are the most widely used pharmaceuticals for intravascular administration (Christiansen, 2005) and are administered to patients at very high doses (up to 200 g per administration) (Pérez and Barceló, 2007). Iopamidol is an ICM that has been widely used worldwide. After administration, iopamidol does not bind to plasma proteins, and at least half of the dose is excreted within $2 \mathrm{~h}$ without being metabolized (Mckinstry et al., 1984). As a result, the wastewater generated in hospitals contains a high concentration of iopamidol derived from patient urine. Hospital wastewater is either directly discharged into the environment or it is treated in a municipal wastewater treatment plant (WWTP) or on-site wastewater treatment facility (Pauwels and Verstraete, 2006). Both the on-site wastewater treatment and the municipal wastewater treatment generally rely on biological treatments such as activated sludge treatment. However, activated sludge treatment does not remove iopamidol, because iopamidol is biologically and chemically inert (Ternes and Hirsch, 2000); removal of iopamidol in municipal WWTPs employing standard activated sludge treatment has been reported to be $0 \%$ (Ternes and Hirsch, 2000), 17\% (Ternes et al., 2007), and 35\% (Kormos et al., 2011). Accordingly, effluents from hospitals and municipal WWTPs are highly contaminated with iopamidol (1.1 $\pm 0.1 \mu \mathrm{g} / \mathrm{L}$ (Ternes et al., 2003), 0.2-4 $\mu \mathrm{g} / \mathrm{L}$ (Busetti et al., 2010), and $16 \pm 3 \mu \mathrm{g} / \mathrm{L}$ (Kormos et al., 2011)). As a result, iopamidol has been detected at high concentrations in river waters that receive these effluents $(0.386 \mu \mathrm{g} / \mathrm{L}$ (Bruchet et al., 2005) and $>0.5 \mu \mathrm{g} / \mathrm{L}$ (Seitz et al., 2006)); these concentrations are a couple of orders of magnitude higher than those of other pharmaceuticals commonly found in effluent.

In a drinking water treatment plant located downstream, water contaminated with iopamidol is likely withdrawn as raw water for drinking. Actually, iopamidol has been frequently detected at high concentrations (2.7 $\mu \mathrm{g} / \mathrm{L}$ (Duirk et al., 2011) and $3.3 \mu \mathrm{g} / \mathrm{L}$ (Simazaki et al., 2015)) in source waters of drinking water. ICMs are one of the most persistent compounds in the drinking water treatment process (Bruchet et al., 2005); iopamidol is particularly difficult to remove during conventional drinking water treatment processes of coagulation, sedimentation, and sand filtration because of its high hydrophilicity (reported log Kow values of -2.42 (Ternes et al., 2007; Kormos et al., 2010) and -0.74 (Simazaki et al., 2015)). Consequently, iopamidol has the potential to come 
into contact with chlorine, which is the final, disinfection step in water treatment. Whereas ICMs including iopamidol are reportedly very stable to monochloramine and chlorine dioxide (Wendel et al., 2014), iopamidol, unlike other ICMs, has been reported to react with chlorine (Wendel et al., 2014; Matsushita et al., 2015). As a consequence of this reaction, iopamidol was not completely mineralized but transformed into many transformation products (TPs) (Wendel et al., 2014; Matsushita et al., 2015). ICMs including iopamidol are widely accepted as safe, given the many toxicity tests required for their registration for clinical use and their long history of use, and given that the toxicities of their possible metabolites in the human body must be adequately investigated. In contrast, the toxicities of the TPs generated during chlorination are not required for ICM registration. However, the toxicity of iopamidol-containing solution reportedly increases after chlorination; Duirk et al. (2011) reported that the cytotoxicity and genotoxicity of natural organic matter (NOM)-containing source water after chlorination was enhanced by the addition of iopamidol when evaluated in mammalian (Chinese hamster ovary; CHO) cells. Wendel et al. (2014) also used CHO cells in chronic cytotoxicity tests and reported that iopamidol-containing solution induced chronic cytotoxicity after chlorination. Furthermore, Matsushita et al. (2015) used the Ames assay to demonstrate that a chlorinated iopamidol-containing solution was mutagenic. These findings clearly show that toxic TPs are generated from iopamidol-containing solution during chlorination, and stress the importance of investigating toxic TPs generated not only during chlorination but also during other water purification processes that involve the transformation of compounds. Ozonation is one such process; it is widely and frequently employed in drinking water treatment plants, and there have been reports that iopamidol is decomposed by a reaction with ozone (Ternes et al., 2003; Huber et al., 2005; Seitz et al., 2008). However, to date, changes in the toxicity of iopamidol-containing solution during ozonation have not been investigated. Moreover, information regarding the toxicity of iopamidol-containing solution after ozonation followed by chlorination has not been obtained.

Therefore, in the present study, we investigated the change in mutagenicity of iopamidol-containing solution during two processes that involve the transformation of compounds (i.e., ozonation, and ozonation followed by chlorination) in an attempt to estimate possible contributors to the observed mutagenicity. Firstly, an Ames assay was conducted to evaluate the mutagenicity of the iopamidol-containing solutions after ozonation and after ozonation followed by chlorination. Secondly, TPs suspected to have contributed to the observed mutagenicity were estimated by means of a correlation analysis between the areas of the TP peaks detected on the LC/MS charts and the observed mutagenicity. Thirdly, the chemical structures of the TPs suspected to have contributed to the observed mutagenicity were estimated by using accurate $m / z$ values and mass spectra obtained in MS/MS analysis with the use of an orbitrap mass spectrometer. Finally, the mutagenicity of each TP was predicted by using a battery of quantitative structure-activity relationship (QSAR) models.

\section{Materials and methods}




\subsection{Ozonation of iopamidol-containing solution}

Stock solution of iopamidol was prepared by dissolving $2.5 \mathrm{~g}$ of iopamidol (Wako Pure Chemical Industries, Ltd., Osaka, Japan) in $100 \mathrm{~mL}$ of Milli-Q water (Milli-Q Advantage, Millipore Co., Bedford, MA, USA) and then passing the solution through a $0.2 \mu \mathrm{m}$ membrane filter (PTFE, Toyo Roshi Kaisya, Tokyo, Japan) to exclude undissolved iopamidol. Phosphate buffer (100 L, 5 mM, pH 7.0) was prepared in a glass vessel, and iopamidol was added to the buffer to a final concentration of $100 \mathrm{mg} / \mathrm{L}$. The solution was divided into five equal parts and then placed in glass reactors. Ozone gas was continuously introduced into the glass reactors at a constant flow rate of $0.3 \mathrm{mg}-\mathrm{O}_{3} /(\mathrm{L} \cdot \mathrm{min})$ by a lab-scale ozone generator (Pretty $\mathrm{O}_{3}$, Metawater Co. Ltd., Tokyo, Japan). The solutions in the glass reactors were subjected to the ozonation for $0,20,60,180$, and $300 \mathrm{~min}$, respectively. Then, each solution was divided into two equal parts. Without quenching the residual ozone, one part was subjected to a solid-phase extraction (see section 2.3) to measure the iopamidol concentration and mutagenicity and to identify TPs, and the other part was subjected to chlorination.

\subsection{Chlorination of ozone-treated iopamidol-containing solution}

Each ozone-treated iopamidol-containing solution was supplemented with sodium hypochlorite at $500 \mathrm{mg} \mathrm{Cl} / \mathrm{L}$ in glass vessels, and left undisturbed in the dark at room temperature for chlorination. After $48 \mathrm{~h}$ of contact time, the calculated amount of sodium ascorbate equivalent to 1.2 times the amount of the residual chlorine was added to the solutions to quench the residual chlorine, and then the solutions were subjected to the solid-phase extraction.

\subsection{Solid-phase extraction}

Solid-phase extraction was performed by using Isolute ENV+ (Biotage AB, Uppsala, Sweden) as follows: $15 \mathrm{~g}$ of Isolute ENV+ bulk solvent was packed in a solid-phase extraction reservoir (volume, $70 \mathrm{~mL}$ ). The solid-phase extraction solvent was activated with sequential addition of 50 $\mathrm{mL}$ of methanol, $100 \mathrm{~mL}$ of Milli-Q water at $\mathrm{pH}$ 2, $50 \mathrm{~mL}$ of methanol, and $100 \mathrm{~mL}$ of Milli-Q water at $\mathrm{pH}$ 7. For the TP extraction, after adjusting the $\mathrm{pH}$ to 2 with $\mathrm{HCl}, 2.5 \mathrm{~L}$ of the samples was circulated through the solid-phase extraction reservoir by a pump (Sep-Pak Concentrator Plus, Waters Corporation, Milford, MA, USA) at a flow rate of $20 \mathrm{~mL} / \mathrm{min}$ for $20 \mathrm{~h}$. After sample extraction, the solid-phase extraction reservoir was washed with $100 \mathrm{~mL}$ of Milli-Q water at $\mathrm{pH} 7$ and then dried by introducing nitrogen gas for $30 \mathrm{~min}$. TPs trapped in the solid-phase extraction reservoir were eluted by introducing $100 \mathrm{~mL}$ of methanol at $1 \mathrm{~mL} / \mathrm{min}$. The eluate was dried under a nitrogen gas flow in a water bath at $45{ }^{\circ} \mathrm{C}$, and then redissolved in $5 \mathrm{~mL}$ of dimethyl sulfoxide (DMSO) to obtain 500-fold concentrates; a part of volatile disinfection by-products (DBPs) may be evaporated by the procedure. The concentrates were used undiluted for the mutagenicity assay (50, 100, and $200 \mu \mathrm{L} /$ plate). The concentrations of the samples were chosen according to the sensitivities of the mutagenicity assay after preliminary experiments with samples of different concentrations.

\subsection{Mutagenicity assay}


Mutagenicities of the samples were evaluated by using the Ames assay. The assay was performed in the absence or presence of a rat liver activation system (S9 mix) with a 20-min preincubation period, as described by Maron and Ames (1983). Oxoid nutrient broth no. 2 was used for the overnight cultures. Two Salmonella typhimurium strains, TA98 (NBRC 14193) and TA100 (NBRC 14194), were purchased from the Biological Resource Center, National Institute of Technology and Evaluation (NBRC, Tokyo, Japan) for use in detecting frameshift-type and base-pair-substitution-type mutagenicities, respectively. Whereas 2-aminoanthracene and 2-nitrofluorene were respectively used as a positive control with and without metabolic activation for both tester strains, DMSO was used as a negative control for all conditions. Revertant colonies (His ${ }^{+}$revertants) were counted after incubation at $37^{\circ} \mathrm{C}$ for $48 \mathrm{~h}$. The number of His ${ }^{+}$revertants in each sample was recorded as the mean value from two plates. To quantify the magnitude of mutagenicity, we calculated the ratio of the number of net $\mathrm{His}^{+}$revertants per plate (i.e., the number of $\mathrm{His}^{+}$revertants $(n)$ minus the number of spontaneous revertants $\left(n_{0}\right)$ ) to the number of spontaneous revertants per plate, defined here as mutagenicity intensity (MI) (Eq. 1).

$$
\mathrm{MI}=\frac{n-n_{0}}{n_{0}}
$$

To facilitate comparison, the mutagenicity of each sample was standardized by using the $\mathrm{MI}_{10}$ value, which we defined as the MI at the dose of sample solution that contained $10 \mathrm{mg}$ of iopamidol before ozonation. The $\mathrm{MI}_{10}$ value was calculated by interpolation from the regression line by using the linearly increasing part of the dose-response curve of the Ames assay for each sample.

\subsection{Iopamidol and TP measurements}

Iopamidol was quantified by using a hybrid quadrupole-orbitrap mass spectrometer (Q Exactive, Thermo Fisher Scientific Inc., Waltham, MA, USA) coupled with liquid chromatography (UltiMate 3000 LC systems, Thermo Fischer Scientific Inc.). To investigate the TPs derived from the iopamidol-containing solution during ozonation and ozonation-chlorination, their accurate masses were similarly determined by using the hybrid quadrupole-orbitrap mass spectrometer coupled with liquid chromatography. Two low-molecular-weight iodic TPs (iodoacetic acid and iodoform) were quantified by using the LC-MS/MS system (LC, UltiMate 3000 LC Systems; MS/MS, Q Exactive, Thermo Fisher Scientific Inc.) and a GC-MS system (QP2010 Plus, Shimadzu Corporation, Kyoto, Japan) equipped with a capillary column (DB-1ms UI, Agilent Technologies, Palo Alto, CA, USA; length, $30 \mathrm{~m}$; internal diameter, $0.25 \mathrm{~mm}$; thickness, $0.25 \mu \mathrm{m})$, respectively. Details regarding measurements are described in Supplementary content.

\subsection{QSAR analysis}

To evaluate the Salmonella mutagenicity of the TPs estimated by the MS/MS analysis, QSAR analyses were conducted by using four types of freely available QSAR software: Toxtree (version 2.6.6) was developed by Ideaconsult Ltd. (Sofia, Bulgaria) and was downloaded from 
http://toxtree.sourceforge.net/; CAESAR (version 2.1.12) was developed as part of the European Union-funded CAESAR project and was used on the VEGANIC platform (version 1.0.8, downloaded from http://www.vega-qsar.eu/); Lazar was developed by In Silico Toxicology GmbH (Basel, Switzerland) and is web-based software (http://www.in-silico.ch/); and T.E.S.T. (version 4.1) was developed by the United States Environmental Protection Agency and was downloaded from http://www.epa.gov/nrmrl/std/qsar/qsar.html. T.E.S.T. included four types of QSAR methodology (i.e., the hierarchical method, FDA method, nearest neighbor method, and consensus method) for predicting Salmonella mutagenicity. In the present study, we predicted the Salmonella mutagenicity of the TPs by using the consensus method because this methodology provided the best prediction results during external validation according to the manufacture's guide. The QSAR models used in the present study predicted Salmonella mutagenicity in the absence and presence of metabolic activation, because the datasets for the QSAR models consisted of mutagenicity data obtained in the absence and presence of metabolic activation (Zeiger, 1987; Kazius et al., 2004; Hansen et al., 2009).

\section{Results and Discussion}

\subsection{Changes in iopamidol concentration following ozonation and ozonation-chlorination}

Iopamidol was gradually decomposed by ozonation, and almost completely disappeared after 180 min of ozone contact time (Fig. 1(a)), consistent with previous findings (Ternes et al., 2003; Huber et al., 2005; Seitz et al., 2008). In contrast, the dissolved organic carbon (DOC) concentration slightly decreased during the ozonation process but $>95 \%$ of it remained at 300 min of ozone contact time even when the iopamidol had completely disappeared (Fig. 1(b)), indicating that iopamidol barely underwent mineralization by ozonation and that organic TPs were present in the samples withdrawn at each contact time.

Even though the samples with ozone contact times of 0, 20, and 60 min contained iopamidol before chlorination (Fig. 1(a)), the iopamidol completely disappeared after the subsequent chlorination (Fig. 1(c)). Iopamidol has been reported to degrade when it reacts with chlorine (Duirk et al., 2011; Wendel et al., 2014; Matsushita et al., 2015), which is in agreement with our result. The DOC concentration decreased during chlorination (compare Fig. 1(d) with (b)), indicating that a portion of the TPs generated during the ozonation was mineralized during the subsequent chlorination. This tendency was enhanced as the ozone contact time was extended, but the DOC remained in solution even at 300 min of ozone contact time. Some of the iopamidol-derived TPs were decomposed to carbon dioxide but the rest remained as organic TPs in the solution even after ozonation-chlorination. 

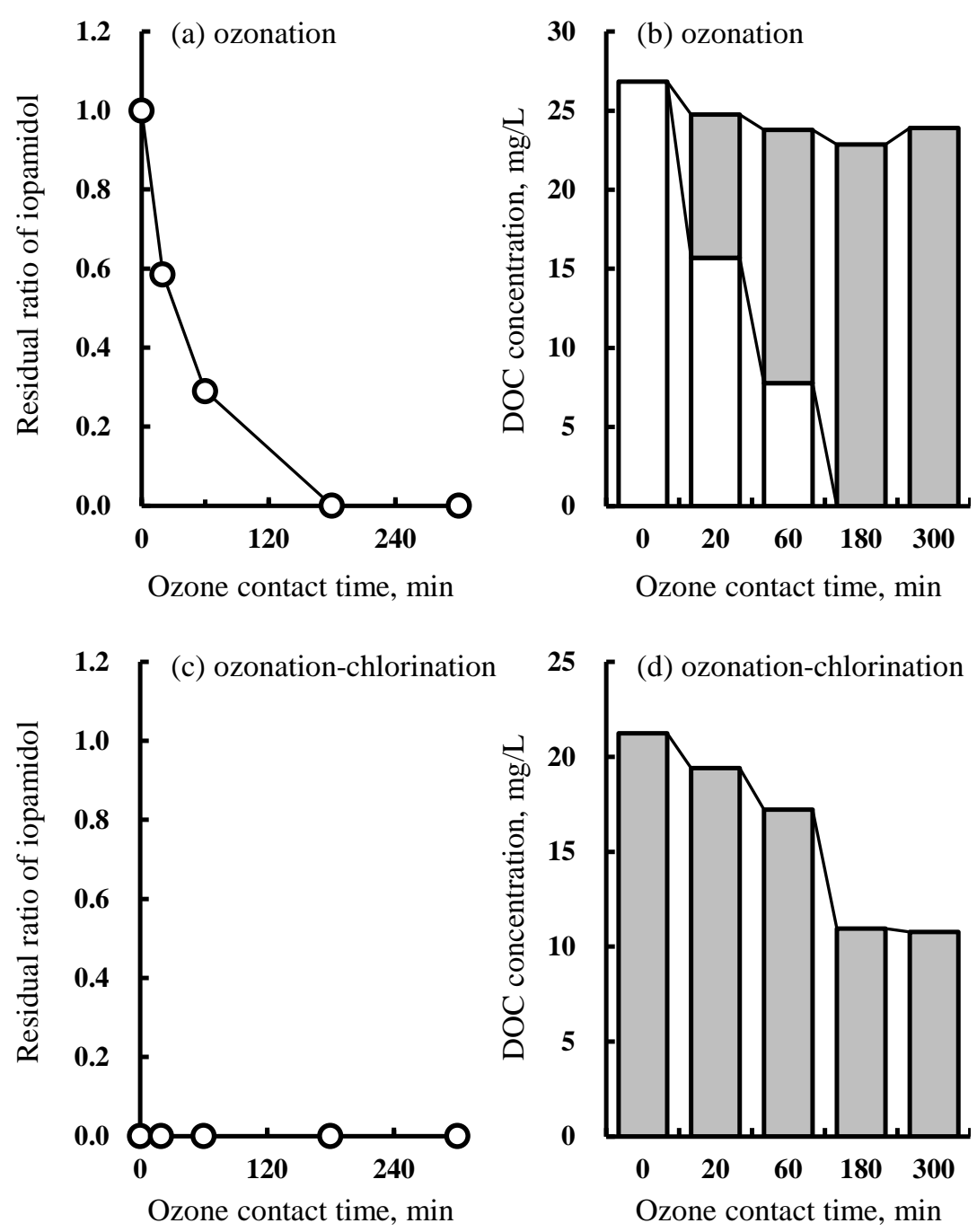

Fig. 1 Changes in iopamidol and DOC concentrations with ozone contact time during ozonation ( $a$ and c) and ozonation-chlorination (b and d). White and gray columns in panels (b) and (d) represent DOC concentrations derived from iopamidol and transformation products, respectively.

\subsection{Changes in mutagenicity following ozonation and ozonation-chlorination}

Mutagenicity induced by the iopamidol-containing solution was calculated as $\mathrm{MI}_{10}$ value from the dose-response curves of Ames assay (Fig. S1). Changes in the mutagenicity of the iopamidol-containing solution with ozone contact time during ozonation and ozonationchlorination are shown in Fig. 2. Because iopamidol is mutagenic to neither the TA98 nor the TA100 Ames tester strain (Matsushita et al., 2015), no mutagenicity was induced by the iopamidol-containing solution before ozonation (white circles at $t=0$ ). During the ozonation process, the $\mathrm{MI}_{10}$ value did not exceed 1 , indicating that no mutagenicity was induced regardless of the Ames strain tested or the presence or absence of metabolic activation (white circles, Figs 2(a)-(d)). These observation clearly show that iopamidol was transformed into ozonation TPs (OTPs) but that the OTPs were not mutagenic.

When the iopamidol-containing solution underwent chlorination without prior ozonation, slight 
mutagenicity was induced in both Ames tester strains regardless of metabolic activation (gray circles at $t=0$ ). This findings indicates that iopamidol was transformed into chlorination TPs (CTPs), some of which were mutagenic. For both Ames tester strains, iopamidol-containing solution has previously been reported to induce mutagenicity in the presence of metabolic activation (Matsushita et al., 2015), which is in agreement with our findings in the present study. However, in contrast to our present findings, iopamidol-containing solution was previously reported to not induce mutagenicity in the absence of metabolic activation in both Ames tester strains (Matsushita et al., 2015). One explanation for this discrepancy might be that the very weak mutagenicities may have been missed in the previous study due to a slight decrease in the sensitivity of the Ames tester strains used.

(a) TA98

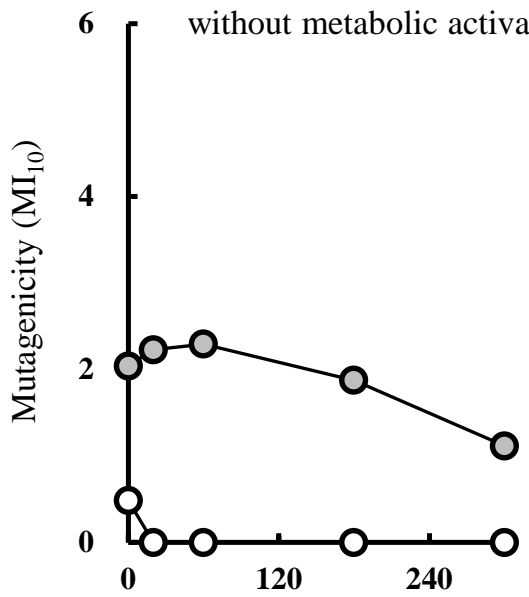

Ozone contact time, $\min$

(c) TA100

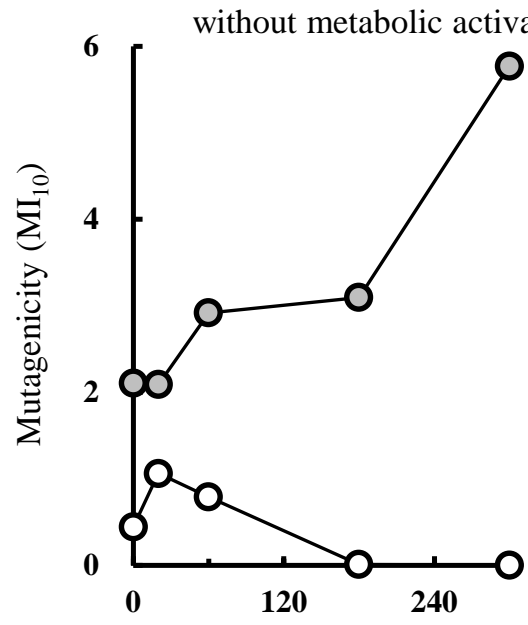

Ozone contact time, min (b) TA98

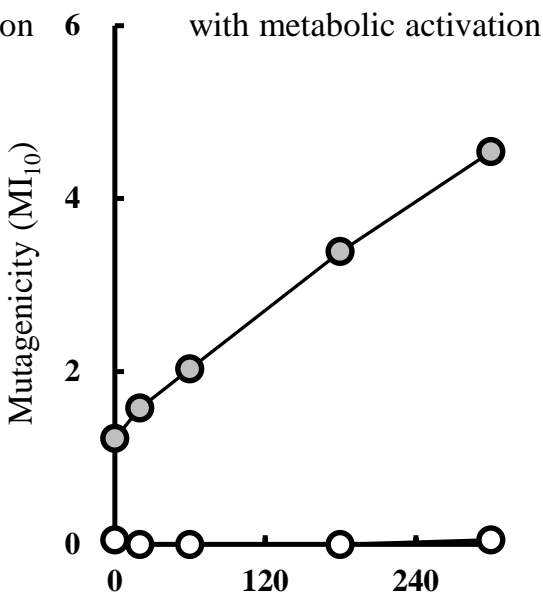

Ozone contact time, min

(d) TA100

with metabolic activation

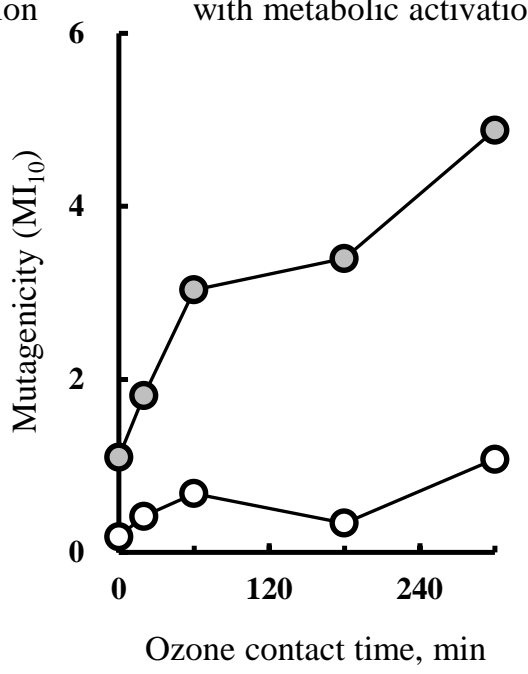

Fig. 2 Changes in mutagenicity of iopamidol-containing solution with ozone contact time during ozonation (white circles) and ozonation-chlorination (gray circles). Mutagenicity is expressed as " $\mathrm{MI}_{10}$ ", which is defined as mutagenicity intensity (i.e., the ratio of the number of net $\mathrm{His}^{+}$revertants per plate to the number of spontaneous revertants per plate) at the dose of sample solution that had initially contained $10 \mathrm{mg}$ of iopamidol (i.e., before ozonation).

In the frameshift-mutagenicity-detecting strain (TA98) without metabolic activation (gray circles, 
Fig. 2(a)), the mutagenicity induced by the ozone-treated iopamidol-containing solution after chlorination was slightly decreased when the ozone contact time was extended, although this change may fall within the margin of error for the sensitivity of the Ames assay. In contrast, the mutagenicity induced for TA98 with metabolic activation clearly increased with ozone contact time (gray circles, Fig. 2(b)), indicating that some of the OTPs reacted with chlorine and were transformed into chlorination OTPs (COTPs). Some of the COTPs were mutagenic. In the base-pair-substitution-mutagenicity detecting strain (TA100), the mutagenicity induced after chlorination increased when the ozone contact time was extended both in the presence and absence of metabolic activation (Figs. 2(c) and (d)). Even though ozonation did not directly transform iopamidol into mutagenic TPs, ozonation could transform iopamidol into precursors of mutagens; some of the OTPs were transformed into mutagenic compounds by subsequent chlorination.

\subsection{Possible contribution of low-molecular-weight TPs to the observed mutagenicities}

Low-molecular-weight iodic TPs such as iodic haloacetic acids and iodic trihalomethanes, which are classified as DBPs, are reported to be produced from iopamidol during chlorination (Duirk et al., 2011; Matsushita et al., 2015). Among these low-molecular-weight iodic TPs, iodoacetic acid has been reported to induce genotoxicity in CHO cells (Plewa et al., 2004; Richardson et al., 2008), while iodoform has been reported to induce mutagenicity in the Ames assay (Haworth et al., 1983). To investigate whether these low-molecular weight iodic TPs contribute to the induced mutagenicity of the iopamidol-containing solution during ozonation-chlorination, we measured the concentrations of iodoacetic acid and iodoform.

Iodoacetic acid was produced during the ozonation-chlorination of iopamidol-containing solution (Fig. S2(a)), reaching a maximum concentration of approximately $4 \mu \mathrm{g} / \mathrm{L}$, which was equivalent to $0.4 \mu \mathrm{g} /$ plate in the Ames assay. However, iodoacetic acid up to $5 \mu \mathrm{g} /$ plate did not induce mutagenicity in the TA100 tester strain regardless of metabolic activation (Fig. S3(a)), and has been reported to induce no mutagenicity with a dose of $\leq 5 \mu \mathrm{g} /$ plate to TA98 tester strain in the presence and absence of metabolic activation (Matsushita et al., 2015). Accordingly, it is unlikely that iodoacetic acid contributed to the mutagenicity observed during the ozonation-chlorination of the iopamidol-containing solution.

Iodoform was also detected during the ozonation-chlorination of the iopamidol-containing solution (Fig. S2(b)). The maximum concentration was approximately $6 \mu \mathrm{g} / \mathrm{L}$, which was equivalent to 0.6 $\mu \mathrm{g} /$ plate in the Ames assay. Iodoform did not induce mutagenicity in the TA100 tester strain at a dose of $\leq 5 \mu \mathrm{g} /$ plate in the presence and absence of metabolic activation (Fig. S3(b)). Matsushita et al. (2015) also reported a lack of mutagenicity induced by $\leq 5 \mu \mathrm{g} /$ plate of iodoform in the presence and absence of metabolic activation in the TA98 tester strain. Therefore, iodoform most likely does not contribute to the mutagenicity observed during the ozonation-chlorination of the iopamidol-containing solution. 


\subsection{Estimation of TPs that contributed to the observed mutagenicity based on Ames mutagenicity data without any modification}

We next attempted to estimate TPs other than the low-molecular-weight TPs discussed above that might contribute to the observed mutagenicity. In the present study, we focused on TPs that were responsible for the mutagenicities induced in TA98 with metabolic activation and in TA100 with and without metabolic activation. TPs responsible for the mutagenicity induced in TA98 without metabolic activation were not assessed further because the change in mutagenicity under these conditions was not large enough to warrant further investigation.

First, to investigate the TPs generated during ozonation-chlorination, the samples that were subjected to the Ames assay were analyzed by LC/MS. Many peaks were detected on the LC/MS total ion chromatogram (TIC) as CTPs and COTPs: 70 peaks were detected with peak areas greater than $1 / 100$ of that of the initially added iopamidol (i.e., before treatment), 16 peaks were at $>1 / 10$, and 2 peaks were at $>1$ (Table S1). Some of these TPs likely contributed to the mutagenicity observed during the ozonation-chlorination process.

(a) TA98

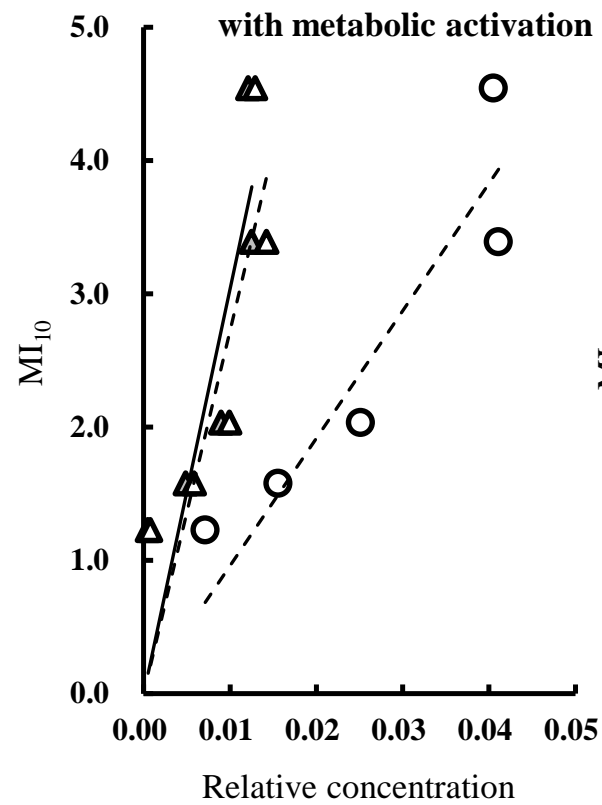

(b) TA100

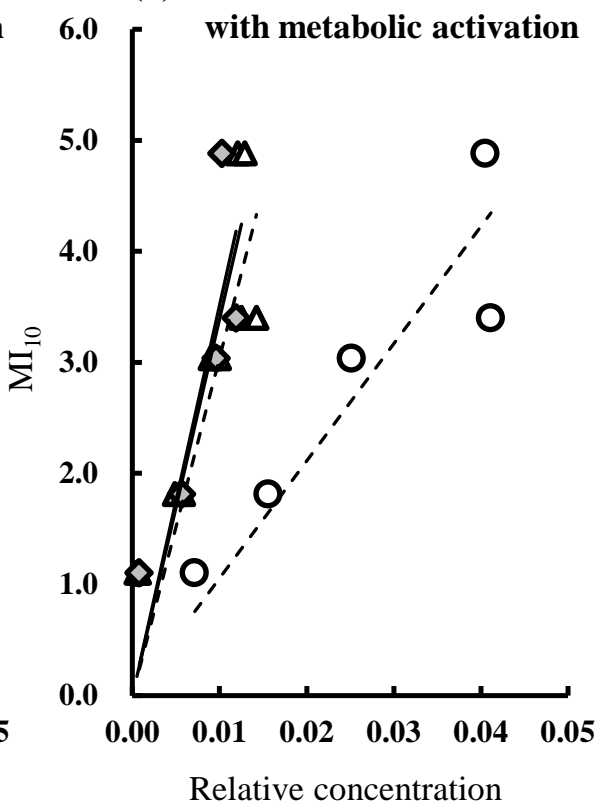

Fig. 3 Relationship between induced mutagenicity and relative concentration of TPs (a, TA98 with metabolic activation; b, TA100 with metabolic activation) that had positive correlations $\left(r^{2}>0.6\right)$ with the observed mutagenicity based on the Ames mutagenicity data without any modification. Relative concentration was calculated by dividing the peak area of each TP by that of the initially added iopamidol (i.e., $100 \mathrm{mg} / \mathrm{L}$ before solid phase extraction). White triangles, Peak \#4 $(\mathrm{m} / \mathrm{z}=379.930$, negative ion mode); gray triangles, Peak \#5 $(\mathrm{m} / \mathrm{z}=381.945$, positive ion mode); gray diamonds, Peak \#33 ( $\mathrm{m} / \mathrm{z}=664.777$, positive ion mode); and white circles, Peak \#51 ( $\mathrm{m} / \mathrm{z}=722.758$, negative ion mode).

Second, to estimate possible TPs that contributed to the observed mutagenicity, we calculated the coefficient of determination between the relative concentration and the observed mutagenicity $\left(\mathrm{MI}_{10}\right)$ for each peak. The relative concentration means the ratio of the area of each peak to that of the initially added iopamidol. The coefficient of determination was determined for the regression 
line through the origin. In the presence of metabolic activation, Peaks \#4 ( $\mathrm{m} / \mathrm{z}=379.930$, negative ion mode), \#5 ( $\mathrm{m} / \mathrm{z}=381.945$, positive ion mode), and \#33 ( $\mathrm{m} / \mathrm{z}=664.777$, positive ion mode) had a positive correlation with the induced mutagenicity, with a coefficient of determination of $>0.6$ for both the TA98 and TA100 tester strains, whereas Peak \#51 ( $\mathrm{m} / \mathrm{z}=722.758$, negative ion mode) had a positive correlation for the TA100 tester strain (Table S1 and Fig. 3). This result indicates that the TPs detected as these peaks potentially contributed to the observed mutagenicity.

In contrast, in the absence of metabolic activation, for the TA100 tester strain, the coefficients of determination were $<0.6$ for all peaks detected (Table S1), indicating that the trends in the concentrations of the TPs detected as peaks did not correlate well with the induced mutagenicity. Candidate contributors to the observed mutagenicity could not be determined in the absence of metabolic activation, possibly because the mutagenicity was induced not by a major TP but by several TPs that had different trends in concentration with time and contributed equally to the mutagenicity.

In the present study, to estimate possible TPs that contributed to the observed mutagenicity, the relationship between their peak areas and the observed mutagenicity. However, it should be noted that the peak area of each TP may not directly reflect its concentration because of possible matrix effects: some TPs that were not detected in the LC/MS analysis may induce mutagenicity. Further study is needed.

\subsection{Estimation of TPs that contributed to the observed mutagenicity based on Ames mutagenicity data derived from COTPs}

In the previous section, the coefficient of determination was calculated by using the regression line through the origin. However, as shown in Fig. 3, mutagenicity was induced even when Peaks \#4, \#5, and \#33 were not detected in the sample before ozonation (relative concentration $=0$, the leftmost plots). These peaks were categorized as COTPs, not CTPs, because the mutagenicity induced without ozonation (i.e., chlorination alone) did not relate to these TP peaks. Mutagenicity induced without ozonation has been attributed to mutagenic CTPs generated during the chlorination of an iopamidol-containing solution (Matsushita et al., 2015). Accordingly, these mutagenic CTPs lowered the coefficient of determination between the relative concentration and the observed mutagenicity because the regression line was assumed to pass through the origin for the calculation of the coefficient of determination. To improve the correlation analysis for selecting candidate COTPs that induce mutagenicity, we divided the observed mutagenicity at time $t\left(\mathrm{MI}_{10}(t)\right)$ into the mutagenicity derived from CTPs at that time $\left(\mathrm{MI}_{10, \mathrm{CTP}}(t)\right)$ and that derived from COTPs $\left(\mathrm{MI}_{10}\right.$, $\operatorname{COTPs}(t))$.

$$
\mathrm{MI}_{10}(t)=\mathrm{MI}_{10, \mathrm{CTPS}}(t)+\mathrm{MI}_{10, \text { COTPs }}(t)
$$

If all of the mutagenic CTPs were identified and the Ames assay was conducted on them to evaluate 
their mutagenicity, $\mathrm{MI}_{10, \mathrm{CTPs}}(t)$ could be determined. However, their standard chemicals are not commercially available, preventing us from performing the Ames assay, and, therefore, we could not directly evaluate $\mathrm{MI}_{10, \mathrm{CTPs}}(t)$.

(a) TA98

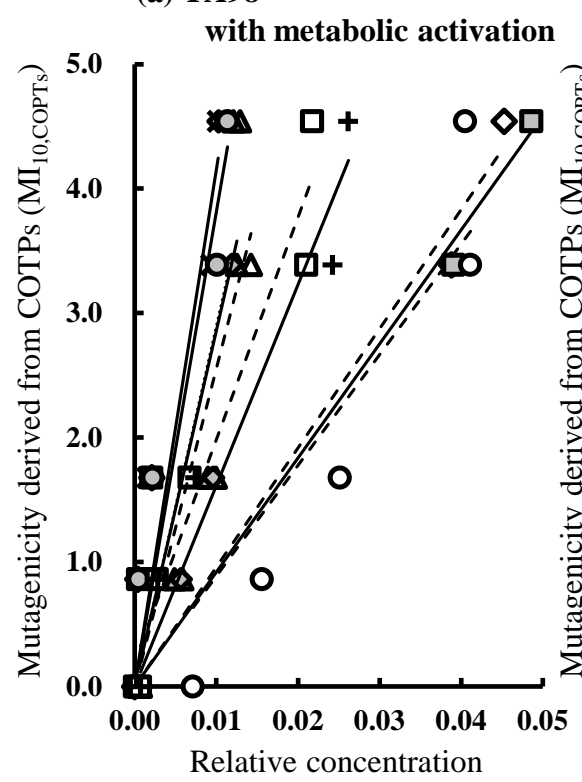

(b) TA100

without metabolic activation (c) TA100

with metabolic activation

Fig. 4 Relationship between mutagenicity derived from COTPs and relative concentration of TPs (a, TA98 with metabolic activation; b, TA100 without metabolic activation; c, TA100 with metabolic activation) that had positive correlations ( $r^{2}>$ 0.6) with the mutagenicity derived from COTPs. Relative concentration was calculated by dividing the peak area of each TP by that of the initially added iopamidol (i.e., $100 \mathrm{mg} / \mathrm{L}$ before solid phase extraction). White triangles, Peak \#4 (m/ $\mathrm{z}=$ 379.930, negative ion mode); gray triangles, Peak \#5 $(\mathrm{m} / \mathrm{z}=381.945$, positive ion mode); gray diamonds, Peak \#33 ( $\mathrm{m} / \mathrm{z}=$ 664.777, positive ion mode); white diamonds, Peak \#34 ( $\mathrm{m} / \mathrm{z}=673.743$, negative ion mode); gray squares, Peak \#35 $(\mathrm{m} / \mathrm{z}=$ 675.757, positive ion mode); crosses, Peak \#46 ( $\mathrm{m} / \mathrm{z}=717.804$, positive ion mode); gray circles, Peak \#49 $(\mathrm{m} / \mathrm{z}=720.767$, positive ion mode); white circles, Peak \#51 ( $\mathrm{m} / \mathrm{z}=722.758$, negative ion mode); white squares, Peak \#55 $(\mathrm{m} / \mathrm{z}=747.778$, negative ion mode); and plus signs, Peak \#58 ( $\mathrm{m} / \mathrm{z}=749.794$, positive ion mode).

Instead, the mutagenicity derived from CTPs was determined to be proportional to the residual ratio of iopamidol before chlorination $\left(C_{\text {iopamidol }}(t) / C_{\text {iopamidol }}(0)\right)$ (Fig. S4), because the CTPs were produced from a reaction between iopamidol and chlorine.

$$
\mathrm{MI}_{10, \mathrm{CTPS}}(t)=\mathrm{MI}_{10, \mathrm{CTPs}}(0) \times \frac{C_{\text {iopamidol }}(t)}{C_{\text {iopamidol }}(0)}
$$

Where

$$
\mathrm{MI}_{10, \mathrm{CTPs}}(0)=\mathrm{MI}_{10}(0)
$$

The mutagenicity intensity derived from COTPs $\left(\mathrm{MI}_{10, \mathrm{COTPs}}(t)\right)$ can thus be calculated from Eq. 5 .

$$
\mathrm{MI}_{10, \mathrm{COTPS}}(t)=\mathrm{MI}_{10}(t)-\mathrm{MI}_{10}(0) \times \frac{C_{\text {iopamidol }}(t)}{C_{\text {iopamidol }}(0)}
$$

The changes in the mutagenicity derived from COTPs calculated by using these procedures (see Fig. 
S4) are shown in Fig. S5. The coefficient of determination between each TP peak area and the mutagenicity derived from COTPs was calculated from the regression line through the origin.

Of 70 TP peaks, 10 were positively correlated with the mutagenicity derived from COTPs, with a coefficient of determination of $>0.6$ (Table S2 and Fig. 4); these 10 peaks included 4 TP peaks that were previously selected. In addition to the 4 TP peaks, Peaks \#34 ( $\mathrm{m} / \mathrm{z}=673.743$, negative ion mode), \#35 ( $\mathrm{m} / \mathrm{z}=675.757$, positive ion mode), \#46 ( $\mathrm{m} / \mathrm{z}=717.804$, positive ion mode), \#49 ( $\mathrm{m} / \mathrm{z}=$ 720.767, positive ion mode), \#55 ( $\mathrm{m} / \mathrm{z}=747.778$, negative ion mode), and \#58 ( $\mathrm{m} / \mathrm{z}=749.794$, positive ion mode) were positively correlated with the mutagenicity derived from COTPs under at least two of three Ames conditions (i.e., combinations of Ames tester strain and the presence or absence of metabolic activation). These results indicate that the TPs detected as these peaks may have contributed to the observed mutagenicity.

\subsection{MS/MS-QSAR analysis to estimate candidate mutagenic TPs}

No mutagenicity was observed during ozonation, clearly demonstrating that the TPs detected during the ozonation process were not mutagenic. To narrow down the candidate mutagenic TPs detected following the ozonation-chlorination process, whether or not the TP peaks selected in sections 3.3 and 3.4 were present in the samples collected during ozonation was confirmed. Peaks \#4, \#5, \#33, and \#49 were not detected, whereas the other TP peaks were detected in the samples collected during the ozonation process at similar concentrations to those in the samples collected during the ozonation-chlorination process (Fig. S6). Given that mutagenicity was not observed during the ozonation process, Peaks \#34, \#35, \#46, \#51, \#55, and \#58 most unlikely contributed to the mutagenicity induced during the ozonation-chlorination process. In contrast, Peaks \#4, \#5, \#33, and \#49 remained as candidate mutagenic TPs.

To obtain the chemical structures of the TPs detected as Peaks \#4, \#5, \#33, and \#49, we performed MS/MS analysis. The MS/MS analysis, combined with accurate mass data, revealed that Peaks \#4 and \#5, detected in the negative and positive ion modes, respectively, were attributable to the same compound. The TPs suspected of contributing to the mutagenicity induced during the ozonationchlorination of the iopamidol-containing solution, listed in Table 1, were estimated as follows: N1-acetyl-5-amino-6-chloro-2-iodobenzene-1,3-dicarboxamide (TP-1, detected as Peaks \#4 and \#5), N3-(1,3-dihydroxypropan-2-yl)-N1,N1,5-trihydroxy-2,4,6-triiodobenzene-1,3-dicarboxamide (TP-2, detected as Peak \#33), and N1-acetyl-5-amino-6-chloro-2-iodobenzene-1,3-dicarboxamide and 3-hydroxy-2-\{3-[(2-hydroxyethoxy)carbonyl]-2,4,6-triiodo-5-nitrobenzoyl $\}$ amino)propanoic acid (TP-3, detected as Peak \#49) (see also Figs. S7-14 for further details of the estimation).

To predict whether TP-1, TP-2, and TP-3 induce mutagenicity, we performed QSAR analysis on the TPs. Because the European Chemicals Agency recommends that predictions be obtained from at least three different methods to avoid false negative results (ECHA, 2008), we used four different types of model (Toxtree, Caesar, Lazar, and T.E.S.T) for the predictions. TP-2 was predicted to be 
Ames-negative by all four QSAR models used (Table 1). These consistent Ames-negative predictions most likely indicate that TP-2 does not contribute to the mutagenicity observed during the ozonation-chlorination of the iopamidol-containing solution. In contrast, three and two of the four QSAR models, respectively, predicted that TP-1 and TP-3 were Ames-positive, suggesting that these TPs were still potentially responsible for the induced mutagenicity.

Table 1 Chemical structures of TPs thought to contribute to the observed mutagenicity and results of QSAR analysis of the TPs. Chromatograms of the TPs are shown in Fig. S15.

\begin{tabular}{|c|c|c|c|c|c|c|c|c|}
\hline & \multirow{2}{*}{ Peak } & \multirow{2}{*}{ m.w. } & \multirow{2}{*}{ Chemical formula and structure } & \multirow{2}{*}{ IUPAC name } & \multicolumn{4}{|c|}{ Results of QSAR analysis } \\
\hline & & & & & Toxtree & Caesar & Lazar & T.E.S.T. \\
\hline TP-1 & $\begin{array}{l}\# 4 \\
\# 5\end{array}$ & 380.9372 & $\begin{array}{c}\mathrm{C}_{10} \mathrm{H}_{9} \mathrm{O}_{3} \mathrm{~N}_{3} \mathrm{ClI} \\
\mathrm{NH}_{2}\end{array}$ & $\begin{array}{l}\text { N1-acetyl-5-amino-6- } \\
\text { chloro-2-iodobenzene-1,3- } \\
\text { dicarboxamide }\end{array}$ & positive & positive & positive & negative \\
\hline TP-2 & \#33 & 663.7695 & $\begin{array}{c}\mathrm{C}_{11} \mathrm{H}_{11} \mathrm{O}_{7} \mathrm{~N}_{2} \mathrm{I}_{3} \\
\stackrel{\mathrm{OH}}{\mathrm{I}}^{\mathrm{I}}\end{array}$ & $\begin{array}{l}\text { N3-(1,3-dihydroxypropan- } \\
\text { 2-yl)-N1,N1,5-trihydroxy- } \\
\text { 2,4,6-triiodobenzene-1,3- } \\
\text { dicarboxamide }\end{array}$ & negative & negative & negative & negative \\
\hline TP-3 & $\# 49$ & 719.7593 & $\begin{array}{c}\mathrm{C}_{13} \mathrm{H}_{11} \mathrm{O}_{9} \mathrm{~N}_{2} \mathrm{I}_{3} \\
\mathbf{N O}_{2}\end{array}$ & $\begin{array}{l}\text { 3-hydroxy-2-(\{3-[(2- } \\
\text { hydroxyethoxy)carbonyl]- } \\
\text { 2,4,6-triiodo-5- } \\
\text { nitrobenzoyl\}amino)propa } \\
\text { noic acid }\end{array}$ & negative & negative & positive & positive \\
\hline
\end{tabular}

\section{Conclusions}

1. The iopamidol-containing solution induced no mutagenicity after ozonation; however, after subsequent chlorination, it did induce mutagenicity in both the TA98 and TA100 Ames tester strains regardless of metabolic activation.

2. To investigate TPs generated during ozonation followed by chlorination, LC/MS analysis was performed on the samples that were periodically withdrawn from the ozone-treated iopamidol-containing solution during the chlorination step. Seventy TP peaks were detected on the LC/MS TIC chart, ten of which showed a positive correlation $\left(r^{2}>0.6\right)$ between peak area and observed mutagenicity. This finding suggests that these TPs may have a role in the observed mutagenicity.

3. To narrow down the possible contributors to the observed mutagenicity, the areas of the ten TP peaks were compared with and without chlorination. Six peaks were detected in the samples without chlorination that did not induce mutagenicity, indicating that these peaks were not related to the observed mutagenicity. In contrast, four peaks were detected only in the samples with chlorination that induced mutagenicity, suggesting that these peaks were still potentially involved in the observed mutagenicity. 
4. To estimate the TPs detected as the above four peaks, MS/MS analysis was performed. Two of the peaks represented the same TP (in negative and positive ion modes), and chemical structures of the remaining three TPs were estimated.

5. To predict whether these remaining three TPs induced mutagenicity, a battery of four QSAR models was applied to the TPs. All of the QSAR models predicted that one of the TPs was non-mutagenic; the other TPs were predicted to be mutagenic by some of the four QSAR models. The latter TPs, as N1-acetyl-5-amino-6-chloro-2-iodobenzene-1,3-dicarboxamide and 3-hydroxy-2-\{3-[(2-hydroxyethoxy)carbonyl]-2,4,6-triiodo-5-nitrobenzoyl \}amino)propanoic acid, remain as strong candidates for the compounds that contributed to the observed mutagenicity during ozonation-chlorination of the iopamidol-containing solution.

\section{Acknowledgments}

This research was supported in part by a Grant-in-Aid for Scientific Research S (No. 24226012) from the Japan Society for the Promotion of Science.

\section{References}

Bruchet, A., Hochereau, C., Picard, C., Decottignies, V., Rodrigues, J.M., Janex-Habibi, M.L., 2005. Analysis of drugs and personal care products in French source and drinking waters: the analytical challenge and examples of application. Water Science and Technology 52, 53-61.

Busetti, F., Linge, K.L., Rodriguez, C., Heitz, A., 2010. Occurrence of iodinated X-ray contrast media in indirect potable reuse systems. Journal of Environmental Science and Health, Part A 45, 542-548.

Christiansen, C., 2005. X-ray contrast media-an overview. Toxicology 209, 185-187.

Duirk, S.E., Lindell, C., Cornelison, C.C., Kormos, J., Ternes, T.A., Attene-Ramos, M., Osiol, J., Wagner, E.D., Plewa, M.J., Richardson, S.D., 2011. Formation of Toxic Iodinated Disinfection By-Products from Compounds Used in Medical Imaging. Environmental Science \& Technology 45, 6845-6854.

ECHA, 2008. Guidance on information requirements and chemical safety assessment Chapter R.7a: endpoint specific guidance. (http://echa.europa.eu/reach_en.asp).

Hainfeld, J.F., Slatkin, D.N., Focella, T.M., Smilowitz, H.M., 2006. Gold nanoparticles: a new X-ray contrast agent. The British Journal of Radiology 79, 248-253.

Hansen, K., Mika, S., Schroeter, T., Sutter, A., ter Laak, A., Steger-Hartmann, T., Heinrich, N., Müller, K.-R., 2009. Benchmark Data Set for in Silico Prediction of Ames Mutagenicity. Journal of Chemical Information and Modeling 49, 2077-2081.

Haworth, S., Lawlor, T., Mortelmans, K., Speck, W., Zeiger, E., 1983. Salmonella mutagenicity test results for 250 chemicals. Environmental Mutagenesis 5, 3-49.

Huber, M.M., GÖbel, A., Joss, A., Hermann, N., LÖffler, D., McArdell, C.S., Ried, A., Siegrist, H., 
Ternes, T.A., von Gunten, U., 2005. Oxidation of Pharmaceuticals during Ozonation of Municipal Wastewater Effluents: A Pilot Study. Environmental Science \& Technology 39, 4290-4299.

Kazius, J., McGuire, R., Bursi, R., 2004. Derivation and Validation of Toxicophores for Mutagenicity Prediction. Journal of Medicinal Chemistry 48, 312-320.

Kormos, J.L., Schulz, M., Kohler, H.-P.E., Ternes, T.A., 2010. Biotransformation of Selected Iodinated X-ray Contrast Media and Characterization of Microbial Transformation Pathways. Environmental Science \& Technology 44, 4998-5007.

Kormos, J.L., Schulz, M., Ternes, T.A., 2011. Occurrence of Iodinated X-ray Contrast Media and Their Biotransformation Products in the Urban Water Cycle. Environmental Science \& Technology 45, 8723-8732.

Matsushita, T., Kobayashi, N., Hashizuka, M., Sakuma, H., Kondo, T., Matsui, Y., Shirasaki, N., 2015. Changes in mutagenicity and acute toxicity of solutions of iodinated X-ray contrast media during chlorination. Chemosphere 135, 101-107.

Mckinstry, D.N., Rommel, A.J., Sugerman, A.A., 1984. Pharmacokinetics, Metabolism, and Excretion of Iopamidol in Healthy Subjects. Investigative Radiology 19, S171-174.

Pérez, S., Barceló, D., 2007. Fate and occurrence of X-ray contrast media in the environment. Anal Bioanal Chem 387, 1235-1246.

Pauwels, B., Verstraete, W., 2006. The treatment of hospital wastewater: an appraisal. Journal of Water and Health 4, 405-416.

Plewa, M.J., Wagner, E.D., Richardson, S.D., Thruston, A.D., Woo, Y.-T., McKague, A.B., 2004. Chemical and Biological Characterization of Newly Discovered Iodoacid Drinking Water Disinfection Byproducts. Environmental Science \& Technology 38, 4713-4722.

Richardson, S.D., Fasano, F., Ellington, J.J., Crumley, F.G., Buettner, K.M., Evans, J.J., Blount, B.C., Silva, L.K., Waite, T.J., Luther, G.W., McKague, A.B., Miltner, R.J., Wagner, E.D., Plewa, M.J., 2008. Occurrence and Mammalian Cell Toxicity of Iodinated Disinfection Byproducts in Drinking Water. Environmental Science \& Technology 42, 8330-8338.

Seitz, W., Jiang, J.-Q., Schulz, W., Weber, W.H., Maier, D., Maier, M., 2008. Formation of oxidation by-products of the iodinated X-ray contrast medium iomeprol during ozonation. Chemosphere 70, 1238-1246.

Seitz, W., Weber, W.H., Jiang, J.-Q., Lloyd, B.J., Maier, M., Maier, D., Schulz, W., 2006. Monitoring of iodinated X-ray contrast media in surface water. Chemosphere 64, 1318-1324.

Simazaki, D., Kubota, R., Suzuki, T., Akiba, M., Nishimura, T., Kunikane, S., 2015. Occurrence of selected pharmaceuticals at drinking water purification plants in Japan and implications for human health. Water research 76, 187-200.

Ternes, T.A., Bonerz, M., Herrmann, N., Teiser, B., Andersen, H.R., 2007. Irrigation of treated wastewater in Braunschweig, Germany: An option to remove pharmaceuticals and musk fragrances. Chemosphere 66, 894-904.

Ternes, T.A., Hirsch, R., 2000. Occurrence and Behavior of X-ray Contrast Media in Sewage Facilities and the Aquatic Environment. Environmental Science \& Technology 34, 2741-2748. 
Ternes, T.A., Stüber, J., Herrmann, N., McDowell, D., Ried, A., Kampmann, M., Teiser, B., 2003. Ozonation: a tool for removal of pharmaceuticals, contrast media and musk fragrances from wastewater? Water research 37, 1976-1982.

Wendel, F.M., Lütke Eversloh, C., Machek, E.J., Duirk, S.E., Plewa, M.J., Richardson, S.D., Ternes, T.A., 2014. Transformation of Iopamidol during Chlorination. Environmental Science \& Technology.

Zeiger, E., 1987. Carcinogenicity of Mutagens: Predictive Capability of the Salmonella Mutagenesis Assay for Rodent Carcinogenicity. Cancer Research 47, 1287-1296. 